\title{
Improving the sequence coverage of integral membrane proteins dur- ing hydrogen/deuterium exchange mass spectrometry experiments.
}

\author{
Ingvar R. Möller, ${ }^{\dagger}$ Marika Slivacka, ${ }^{\dagger}$ Jiří Hausner, ${ }^{\ddagger}$ Anne Kathrine Nielsen, ${ }^{\S}$ Eliška Pospíšilová, ${ }^{\ddagger}$ \\ Patrick S. Merkle, ${ }^{\dagger}$ Růžena Lišková, ${ }^{\ddagger \#}$ Marek Polák, ${ }^{\ddagger \#}$ Claus J. Loland, ${ }^{\S}$ Alan Kádek, ${ }^{\ddagger \#}$ Petr Man, ${ }^{\ddagger \#}$ \\ Kasper D. Rand ${ }^{\dagger *}$ \\ ${ }^{\dagger}$ Department of Pharmacy, University of Copenhagen, Universitetsparken 2, Copenhagen E, DK-2100, Denmark. \\ ‡ BioCeV - Institute of Microbiology of the CAS, Prumyslova 595, CZ-252 50 Vestec, Czech Republic \\ \# Faculty of Science, Charles University, Hlavova 8, CZ-128 20 Prague, Czech Republic \\ $\S$ Laboratory for Membrane Protein Dynamics, Department of Neuroscience, University of Copenhagen, Blegdamsvej 3, Co- \\ penhagen N, DK-2200, Denmark. \\ * To whom correspondence should be addressed: kasper.rand@sund.ku.dk \\ Supplementary information
}

\section{Table of Contents}

S-2 ..... Figure S-1. Sequence coverage of Phos B following digestion by immobilized proteases.

S-4 ..... Figure S-2. Sequence coverage of Phos B following in-solution digestion.

S-7 ...... Figure S-3. Sequence coverage of ClC-ec1 following digestion by immobilized proteases.

S-8 ...... Figure S-4. Sequence coverage of ClC-ec1 following in-solution digestion.

S-9 ..... Figure S-5. Sequence coverage of LeuT following digestion by immobilized proteases.

S-10 ...... Figure S-6. Sequence coverage of LeuT following in-solution digestion.

S-11 ..... Figure S-7. Sequence coverage of DAT following digestion by immobilized proteases.

S-12 ...... Figure S-8. Sequence coverage of DAT following in-solution digestion.

S-13 ...... Figure S-9. Sequence coverage of SERT following in-solution digestion.

S-14 ...... Table S-1. Extended overview of the digestion results obtained by the different proteases.

S-15 ..... Table S-2. Comparison of the effect of different quench conditions on the digestion of phosphorylase B. 
MSRPLSDQDKRKQISVRGLAGVENVSDLKKNFNRHLHFTLVKDRNVATPRDYYFALAHTVRDHLVDRWIRTQQHYYAKDPKRIYYLSLELYMGRTLQNTM

10
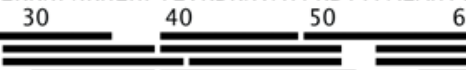

60

70

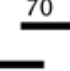

80

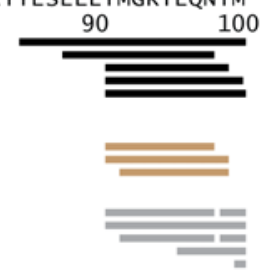

VNLALENACDEATYQLGLDMEELEEIEEDAGLGNGGLGRLAACFLDSMATLGLAAYGYGIRYEFGIFNQKICGGWQMEEADDWLRYGNPWEKARPEFTLP

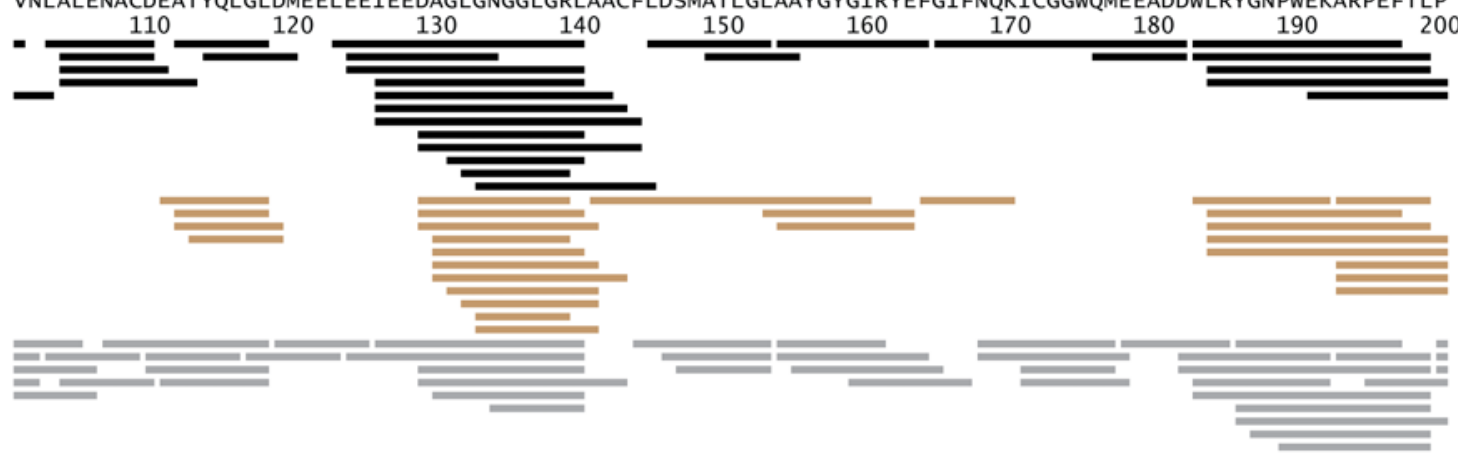

VHFYGRVEHTSQGAKWVDTQVVLAMPYDTPVPGYRNNVVNTMRLWSAKAPPYFNLKDFNVGGYIQAVLDRNLAENISRVLYPNDKFFEGKELRLKQEYFV

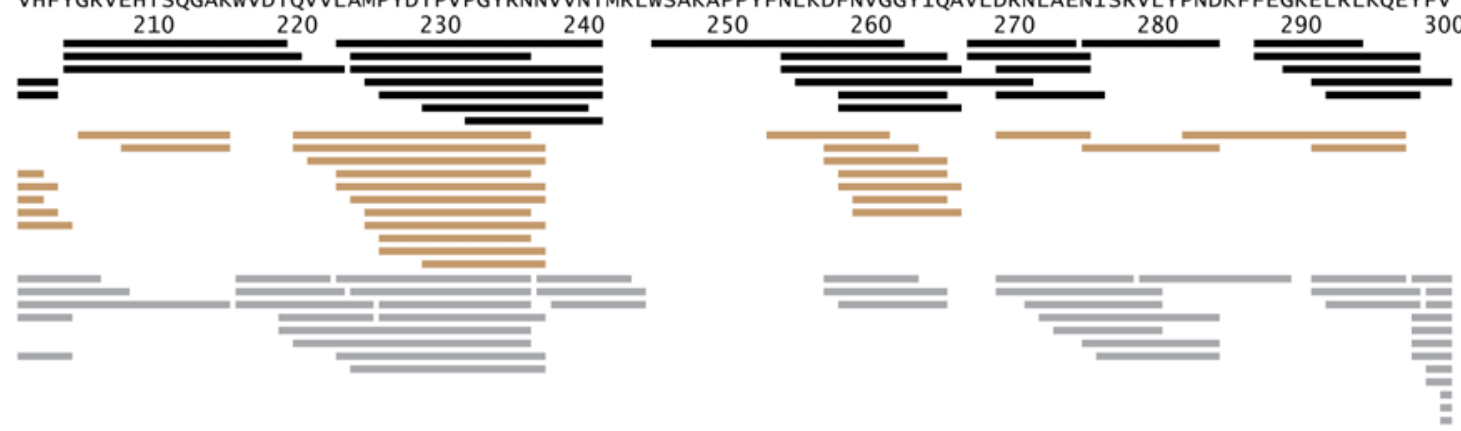

VAATLQDIIRRFKSSKFGCRDPVRTNFDAFPDKVAIQLNDTHPSLAIPELIRILVDLERLDWDKAWDVTVKTCAYTNHTVLPEALERWPVHLMETLLPRH

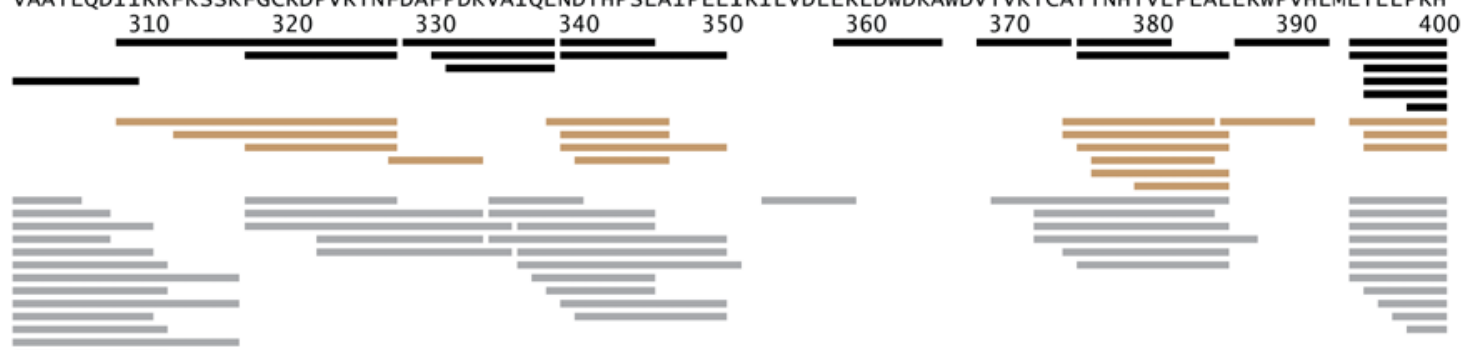



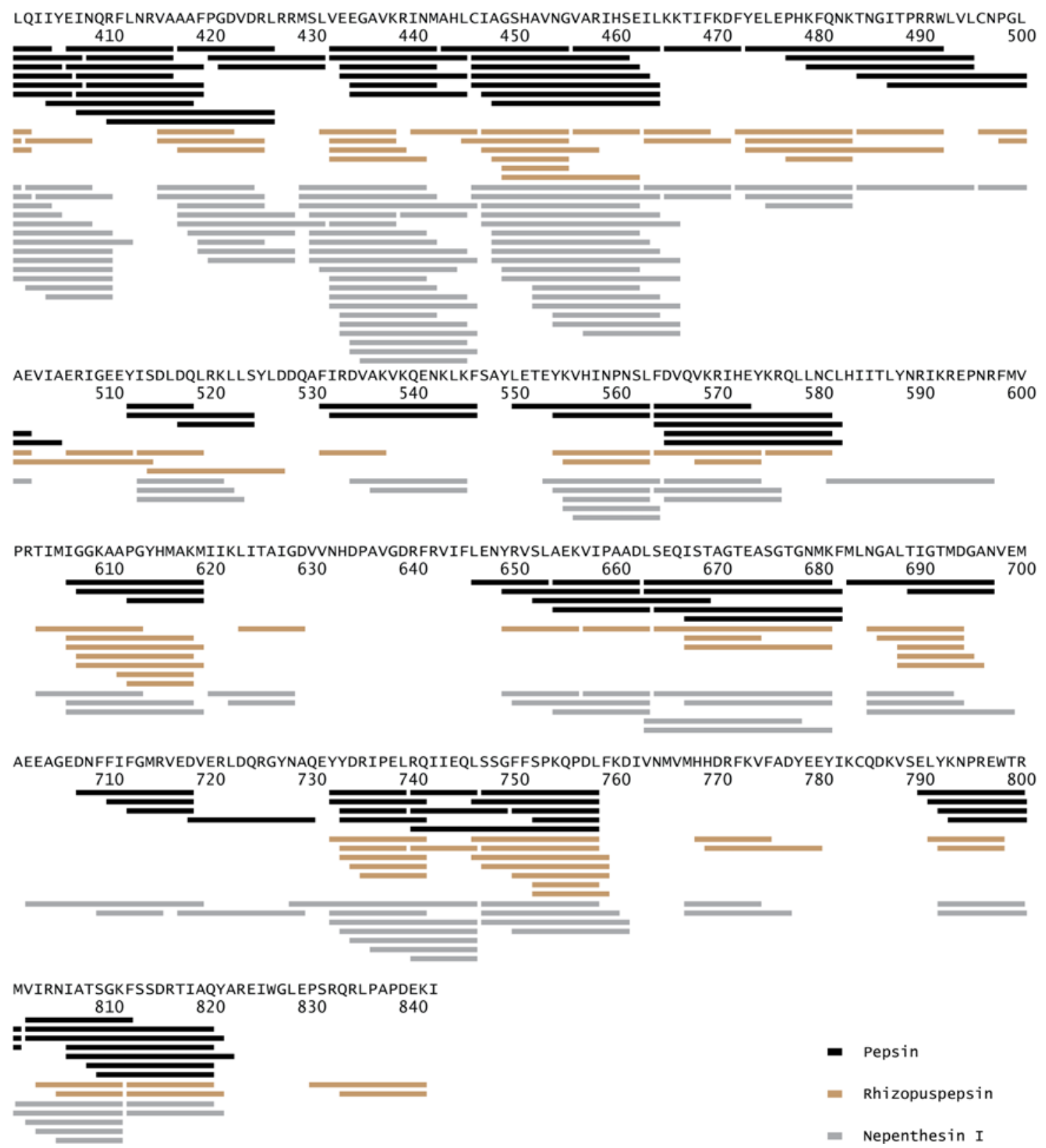

Figure S-1. Sequence coverage of Phos B following digestion by immobilized proteases. The digestion of Phos B resulted in 178 identified peptides covering $79.9 \%$ of the sequence following digestion by immobilized pepsin (black); 164 identified peptides covering $67.9 \%$ of the sequence following digestion by immobilized rhizopuspepsin (light brown); 260 peptides covering $79.0 \%$ of the sequence following digestion by immobilized nepenthesin I (gray). 
MSRPLSDQDKRKQISVRGLAGVENVSDLKKNFNRHLHFTLVKDRNVATPRDYYFALAHTVRDHLVDRWIRTQQHYYAKDPKRIYYLSLELYMGRTLQNTM

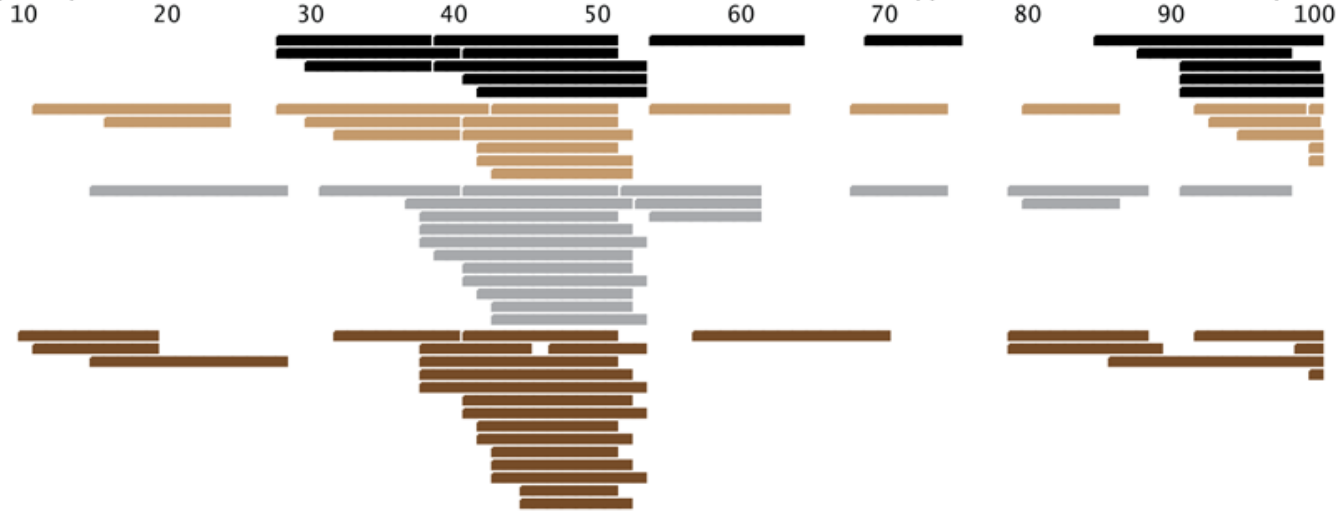

VNLALENACDEATYQLGLDMEELEEIEEDAGLGNGGLGRLAACFLDSMATLGLAAYGYGIRYEFGIFNOKICGGWQMEEADDWLRYGNPWEKARPEFTLP
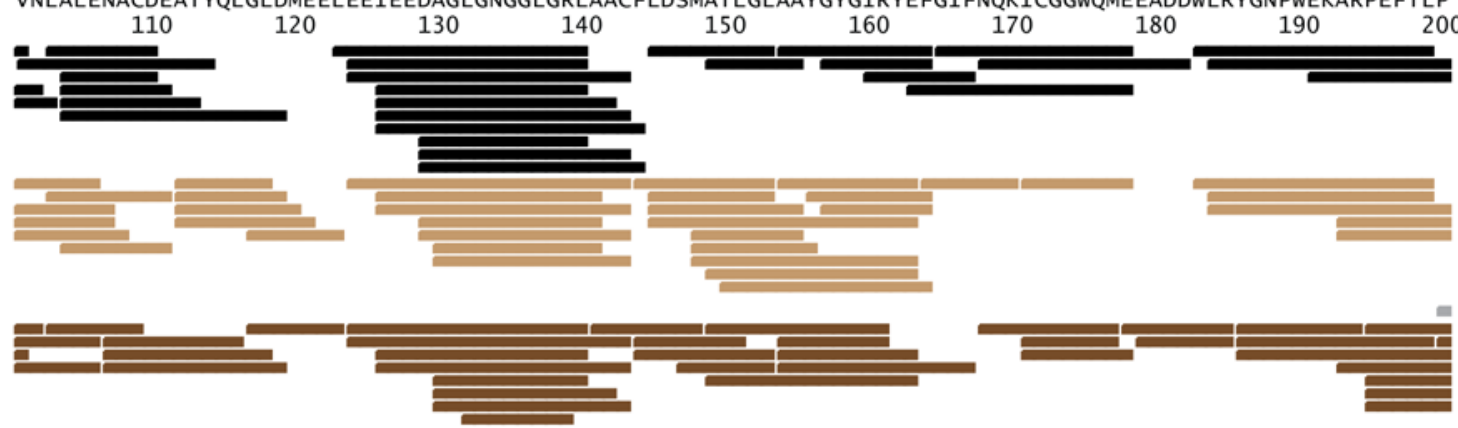

VHFYGRVEHTSQGAKWVDTQVVLAMPYDTPVPGYRNNVVNTMRLWSAKAPPYFNLKDFNVGGYIQAVLDRNLAENISRVLYPNDKFFEGKELRLKQEYFV
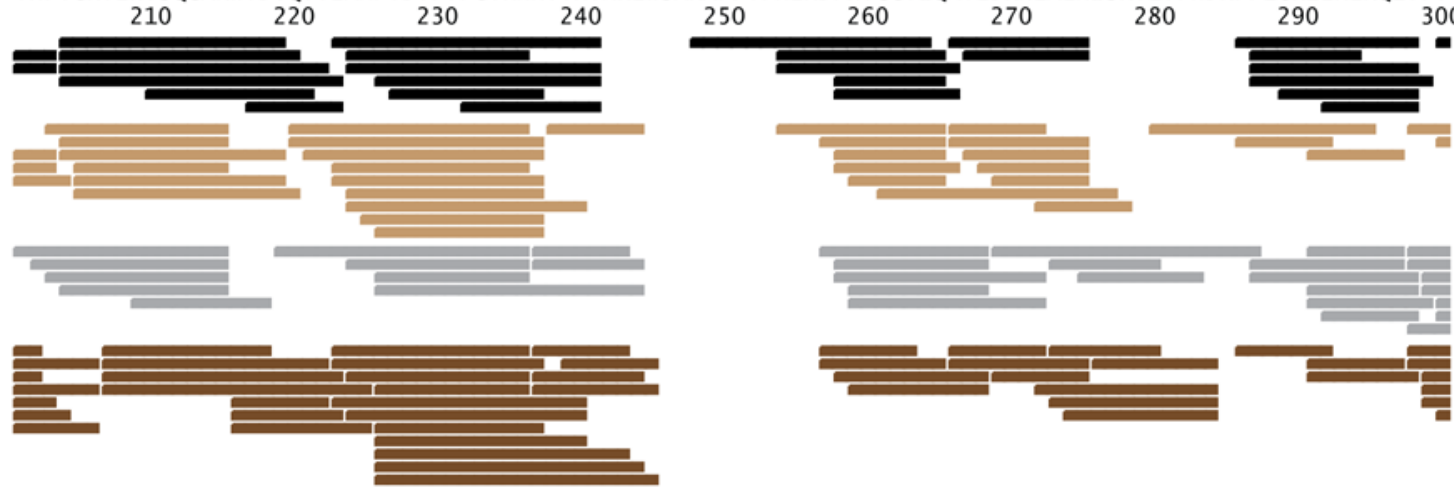

VAATLQDIIRRFKSSKFGCRDPVRTNFDAFPDKVAIQLNDTHPSLAIPELIRILVDLERLDWDKAWDVTVKTCAYTNHTVLPEALERWPVHLMETLLPRH

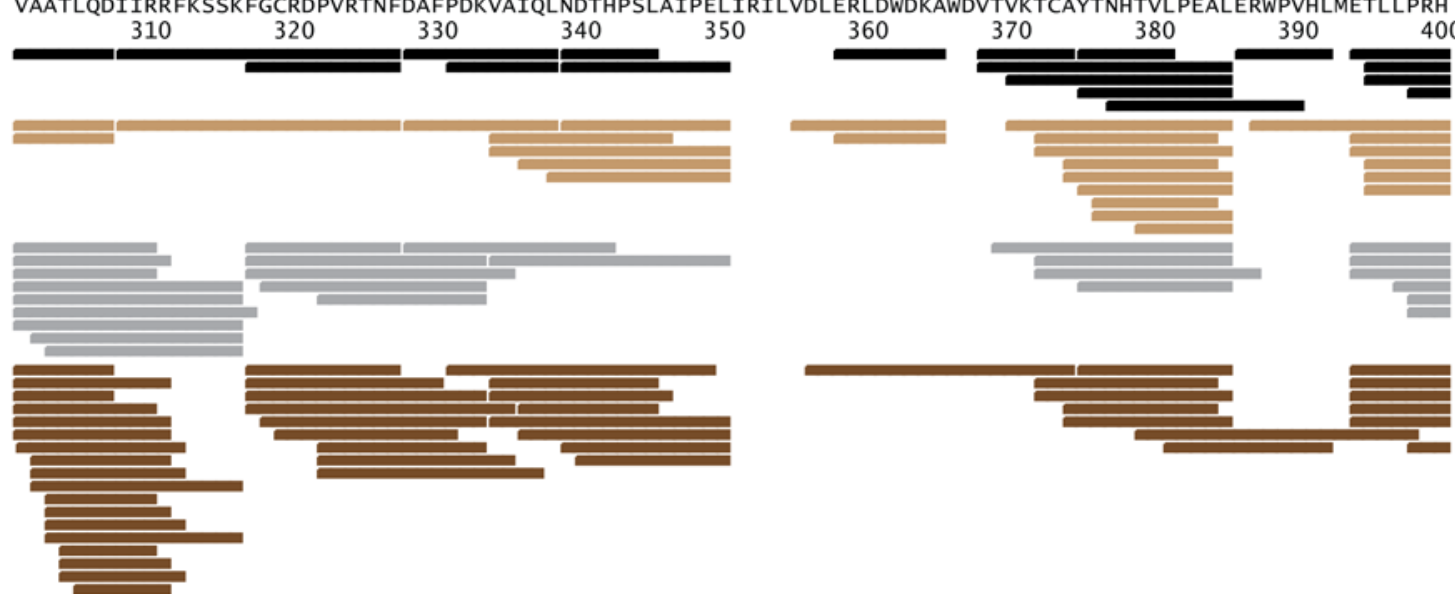




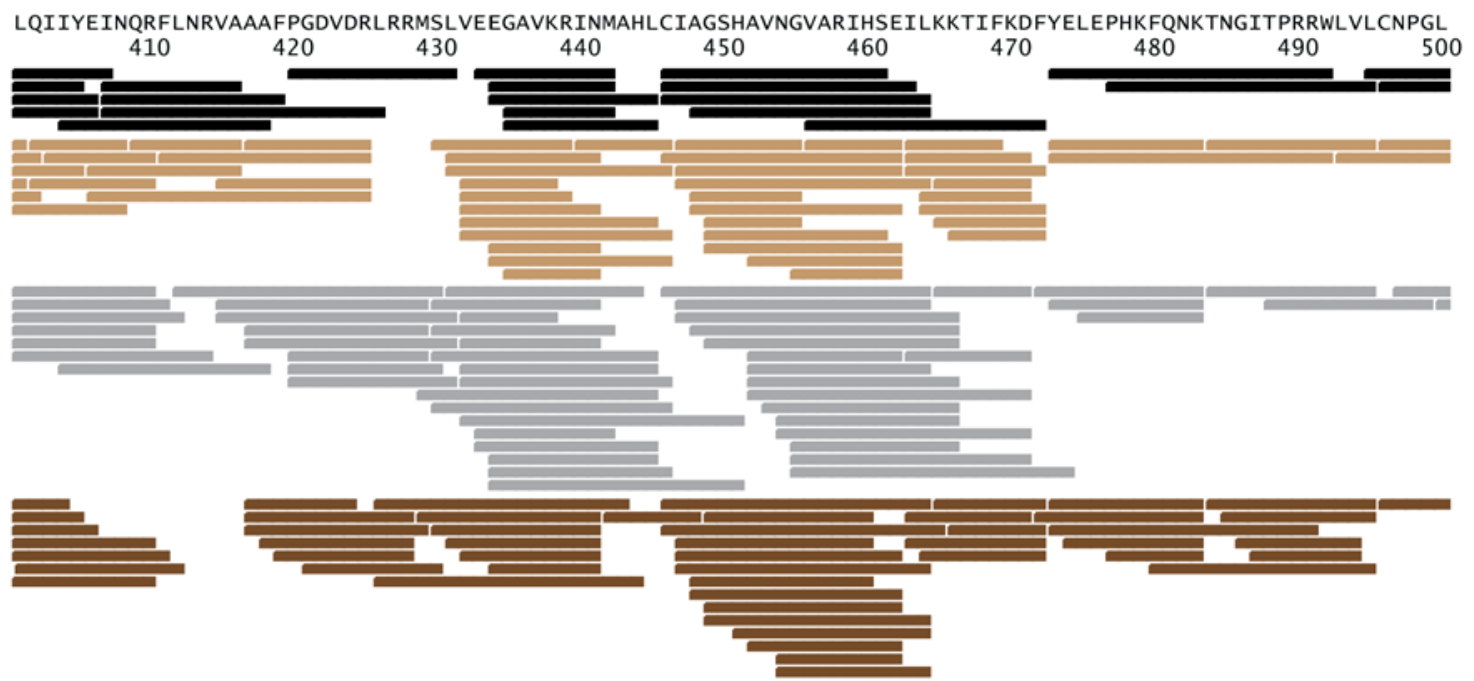

AEVIAERIGEEYISDLDQLRKLLSYLDDQAFIRDVAKVKQENKLKFSAYLETEYKVHINPNSLFDVQVKRIHEYKRQLLNCLHIITLYNRIKREPNRFMV

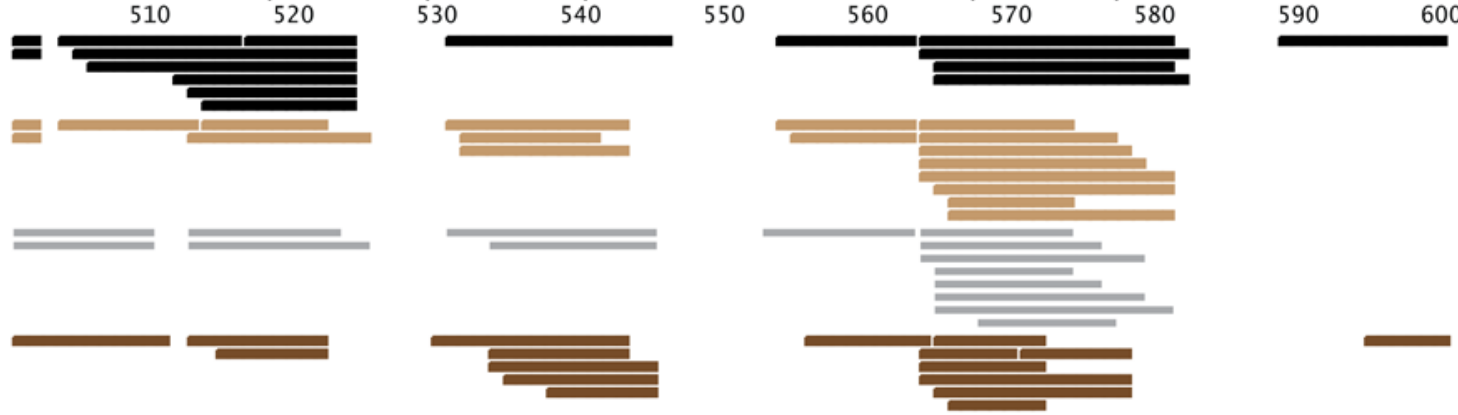

PRTIMIGGKAAPGYHMAKMIIKLITAIGDVVNHDPAVGDRFRVIFLENYRVSLAEKVIPAADLSEQISTAGTEASGTGNMKFMLNGALTIGTMDGANVEM

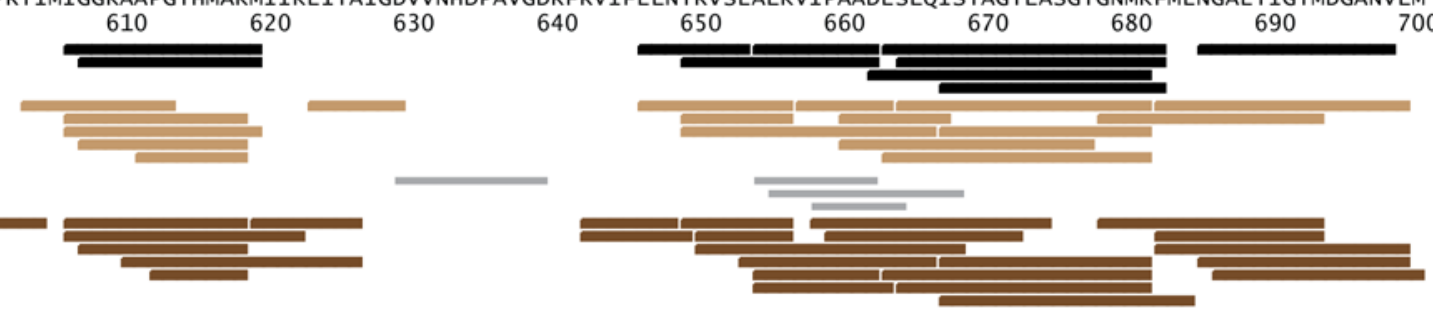

AEEAGEDNFFIFGMRVEDVERLDQRGYNAQEYYDRIPELRQIIEQLSSGFFSPKQPDLFKDIVNMVMHHDRFKVFADYEEYIKCQDKVSELYKNPREWTR

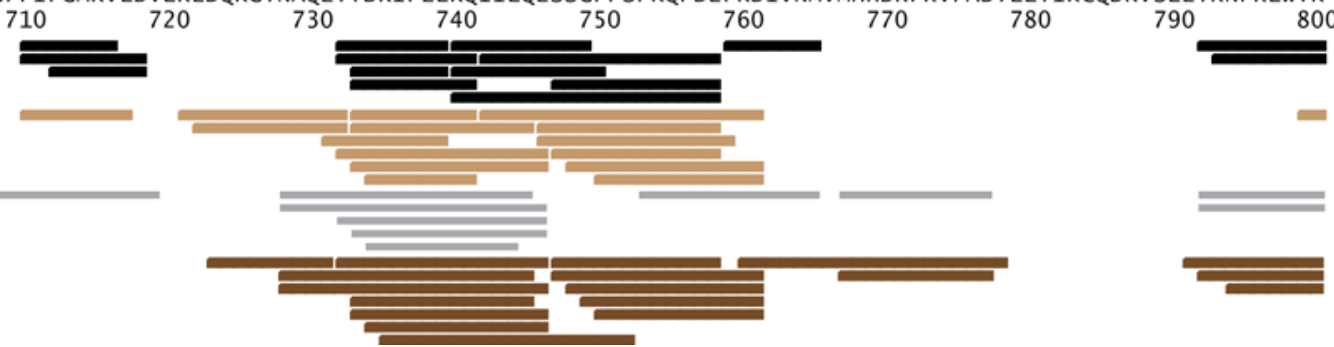




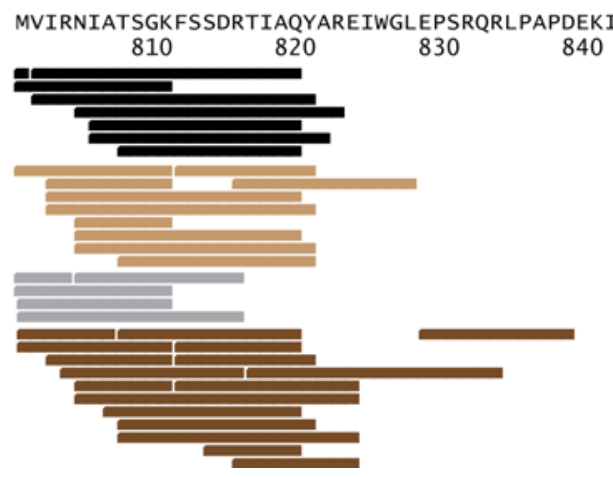

- Pepsin

- Rhizopuspepsin

$=$ Nepenthesin $\mathrm{I}$

- Nepenthesin II

Figure S-2. Sequence coverage of Phos B following in-solution digestion. The digestion of Phos B resulted in 150 identified peptides covering $77.2 \%$ of the sequence following in-solution digestion by pepsin (black); 214 identified peptides covering $79.2 \%$ of the sequence following in-solution digestion by rhizopuspepsin (light brown); 150 identified peptides covering 61.0\% of the sequence following in-solution digestion by nepenthesin I (gray); 269 identified peptides covering 84.4\% of the sequence following in-solution digestion by nepenthesin II (dark brown). 

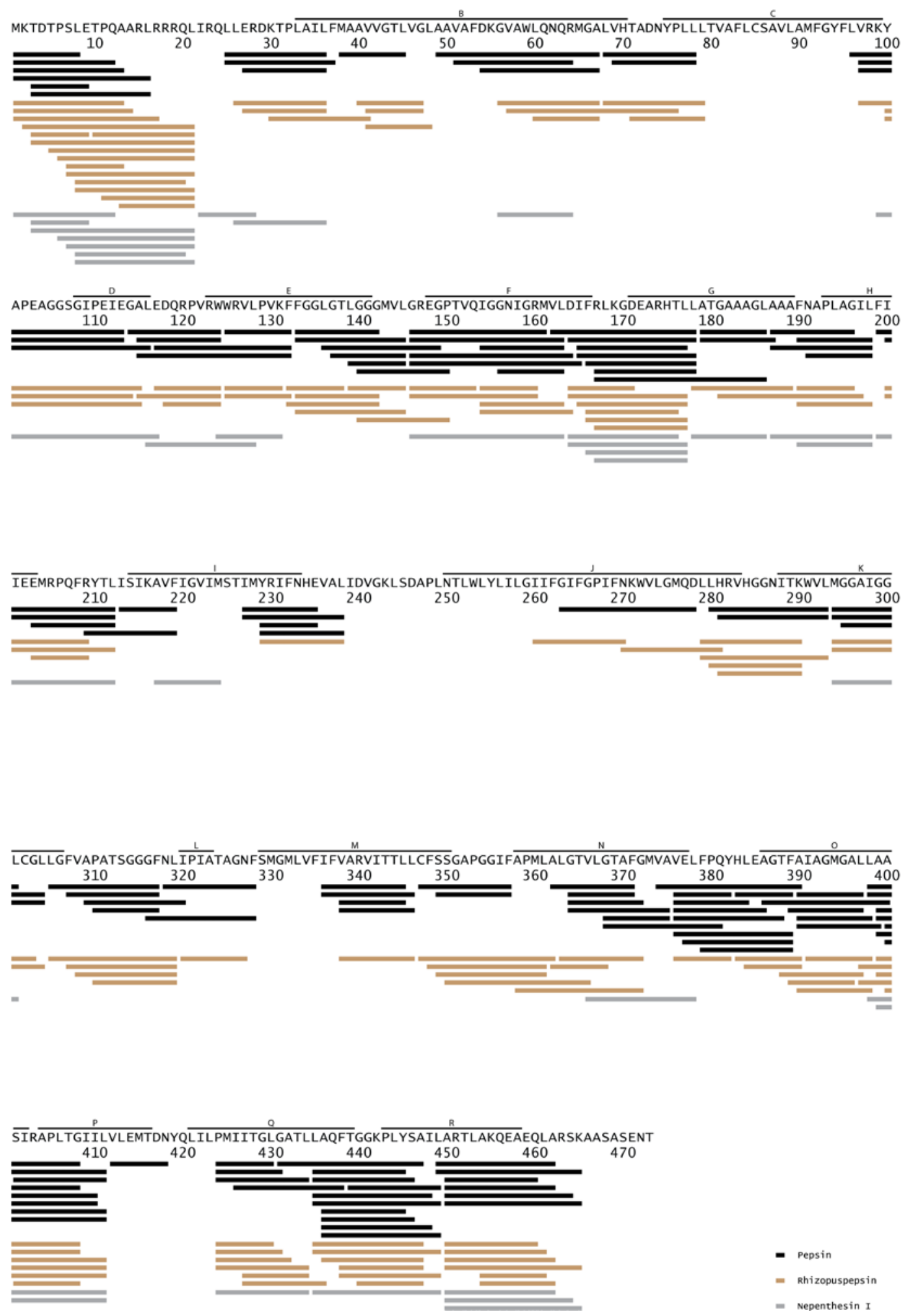

Figure S-3. Sequence coverage of ClC-ec1 following digestion by immobilized proteases. The digestion of ClC-ec1 resulted in 124 identified peptides covering $82.2 \%$ of the sequence following digestion by immobilized pepsin (black); 111 identified peptides covering $79.1 \%$ of the sequence following digestion by immobilized rhizopuspepsin (light brown); 32 identified peptides covering $48.6 \%$ of the sequence following digestion by immobilized nepenthesin I (gray). 


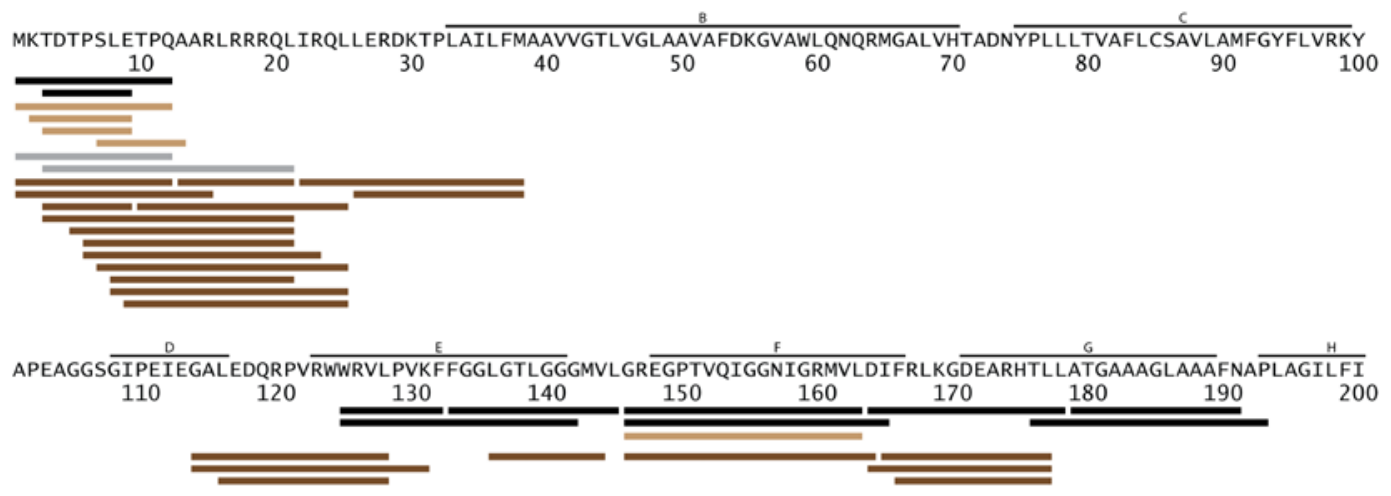

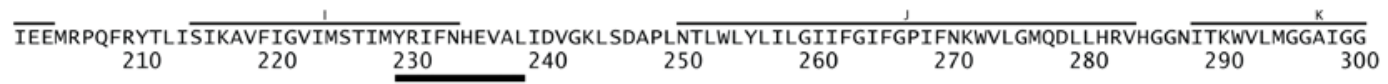

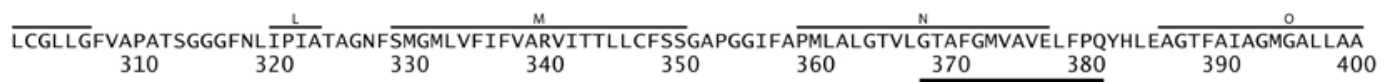

$310 \quad 320$

$330 \quad 340 \quad 350$

360
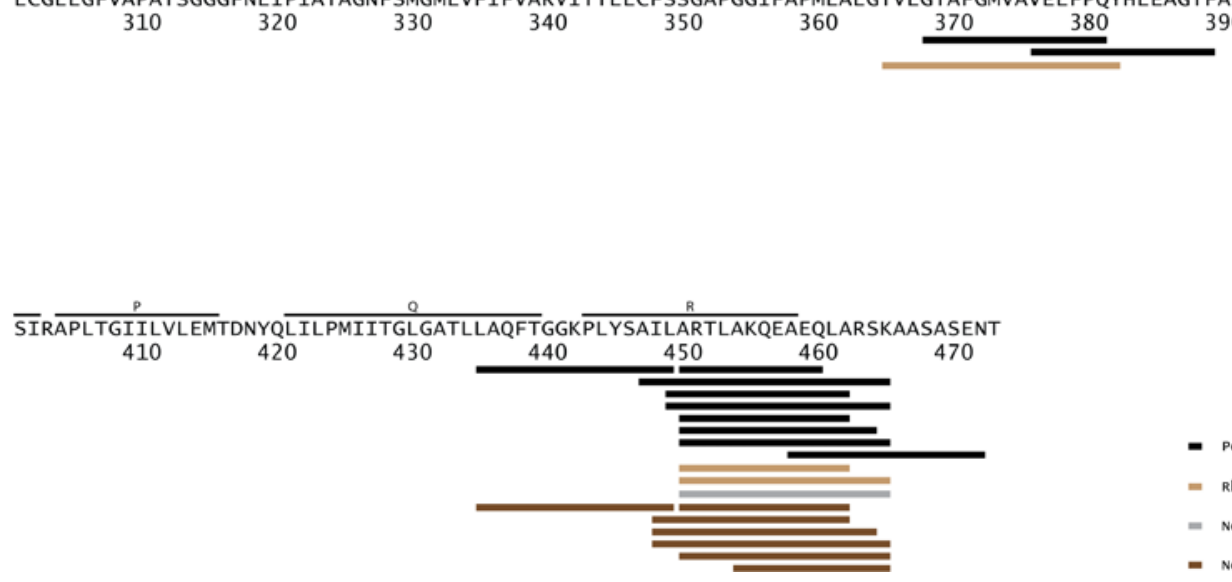

- Pepsin

$=$ Rhizopuspepsin

- Nepenthesin I

- Nepenthesin II

Figure S-4. Sequence coverage of ClC-ec1 following in-solution digestion. The digestion of ClC-ec1 resulted in 22 identified peptides covering $31.9 \%$ of the sequence following in-solution digestion by pepsin (black); 8 identified peptides covering 13.7\% of the sequence following in-solution digestion by rhizopuspepsin (light brown); 30 identified peptides covering $27.1 \%$ of the sequence following in-solution digestion by nepenthesin II (dark brown). Less than $5 \%$ of the sequence was covered by peptides identified following digestion by nepenthesin I (gray). 

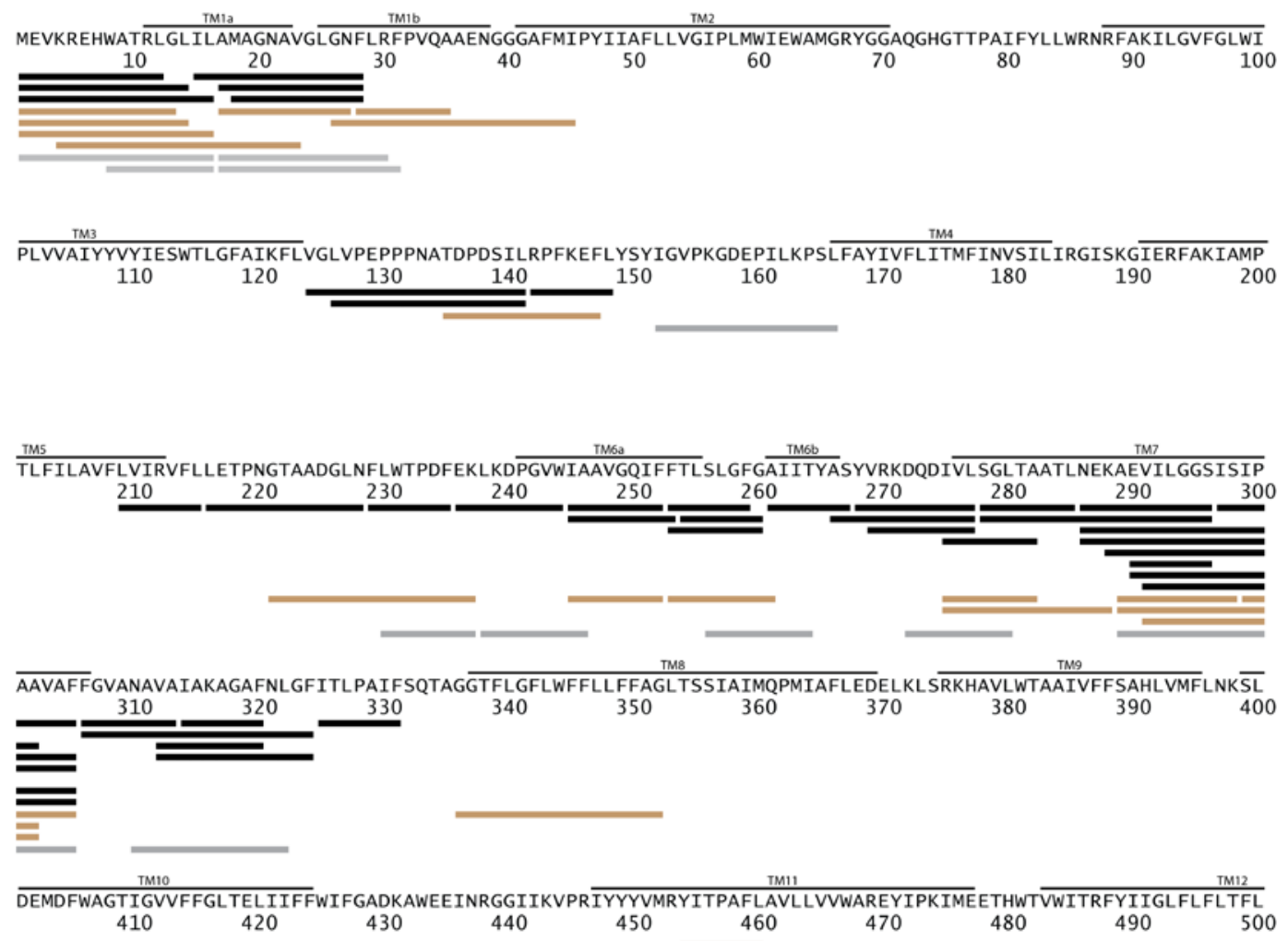

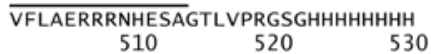

- Pepsin

- Rhizopuspepsin

$=$ Nepenthesin I

Figure S-5. Sequence coverage of LeuT following digestion by immobilized proteases. The digestion of LeuT resulted in 39 identified peptides covering $33.2 \%$ of the sequence following digestion by immobilized pepsin (black); 19 identified peptides covering $27.7 \%$ of the sequence following digestion by immobilized rhizopuspepsin (light brown); 11 identified peptides covering $21.1 \%$ of the sequence following digestion by immobilized nepenthesin I (gray). 


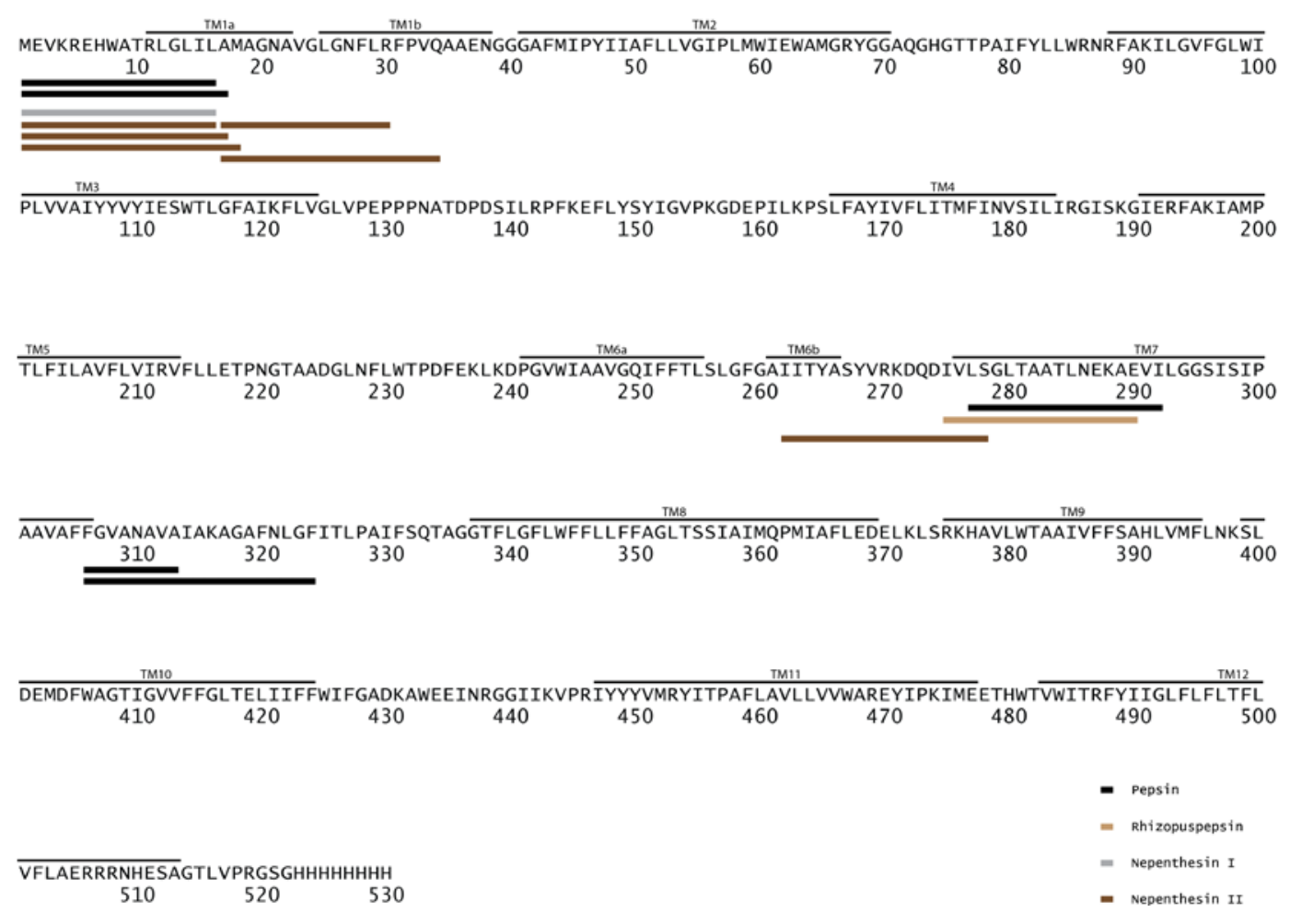

Figure S-6. Sequence coverage of LeuT following in-solution digestion. The digestion of LeuT resulted in 5 identified peptides covering $9.8 \%$ of the sequence following in-solution digestion by pepsin (black); 6 identified peptides covering 9.6\% of the sequence following insolution digestion by nepenthesin II (dark brown). Digestion by rhizopuspepsin (light brown) and nepenthesin I (gray) were largely unsuccessful resulting in less than $5 \%$ of the sequence coverage. 

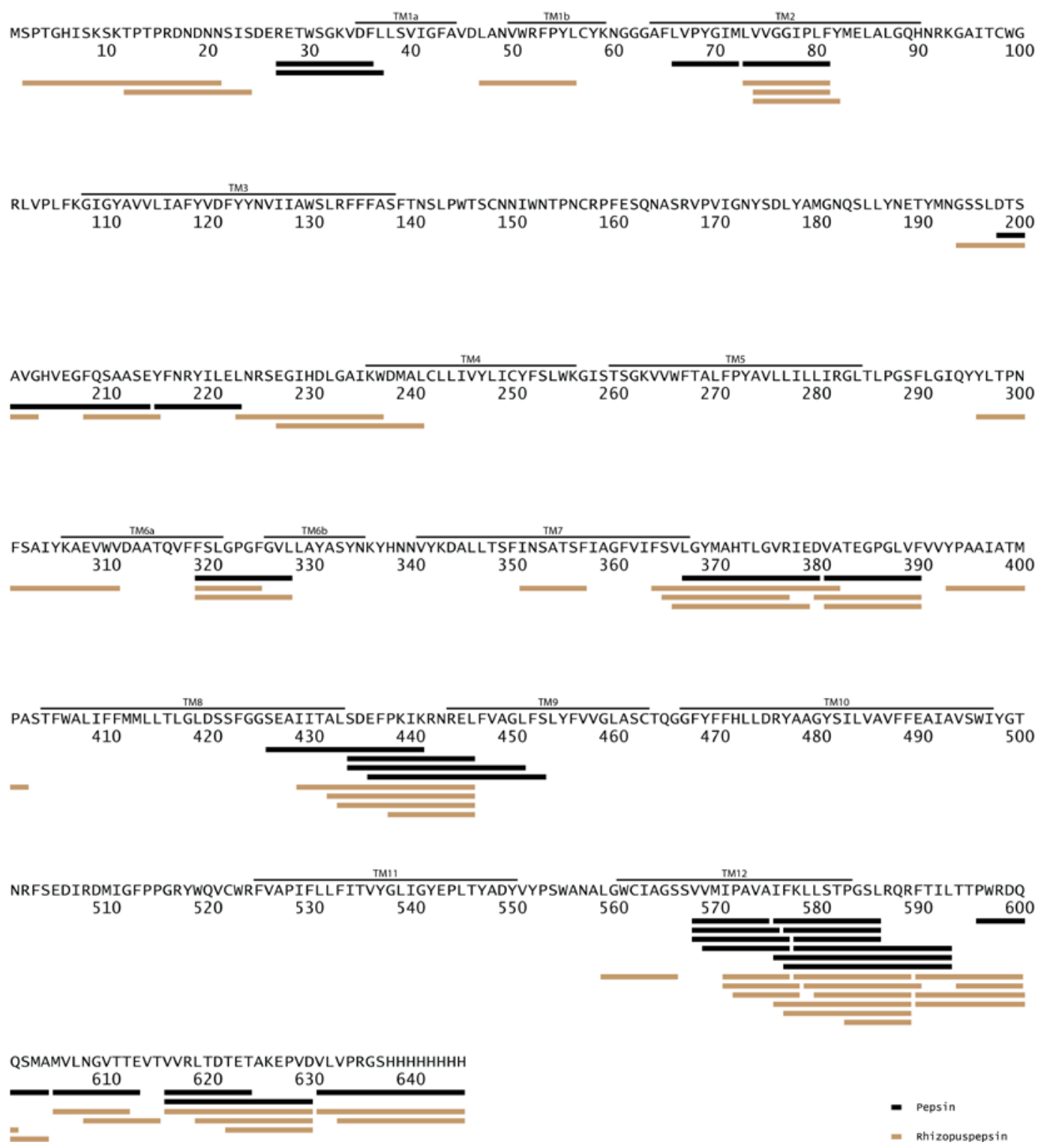

Figure S-7. Sequence coverage of DAT following digestion by immobilized proteases. The digestion of DAT resulted in 28 identified peptides covering $29.3 \%$ of the sequence following digestion by immobilized pepsin (black); 45 identified peptides covering $38.9 \%$ of the sequence following digestion by immobilized rhizopuspepsin (light brown). Digestion by immobilized nepenthesin I on DAT was not performed. 


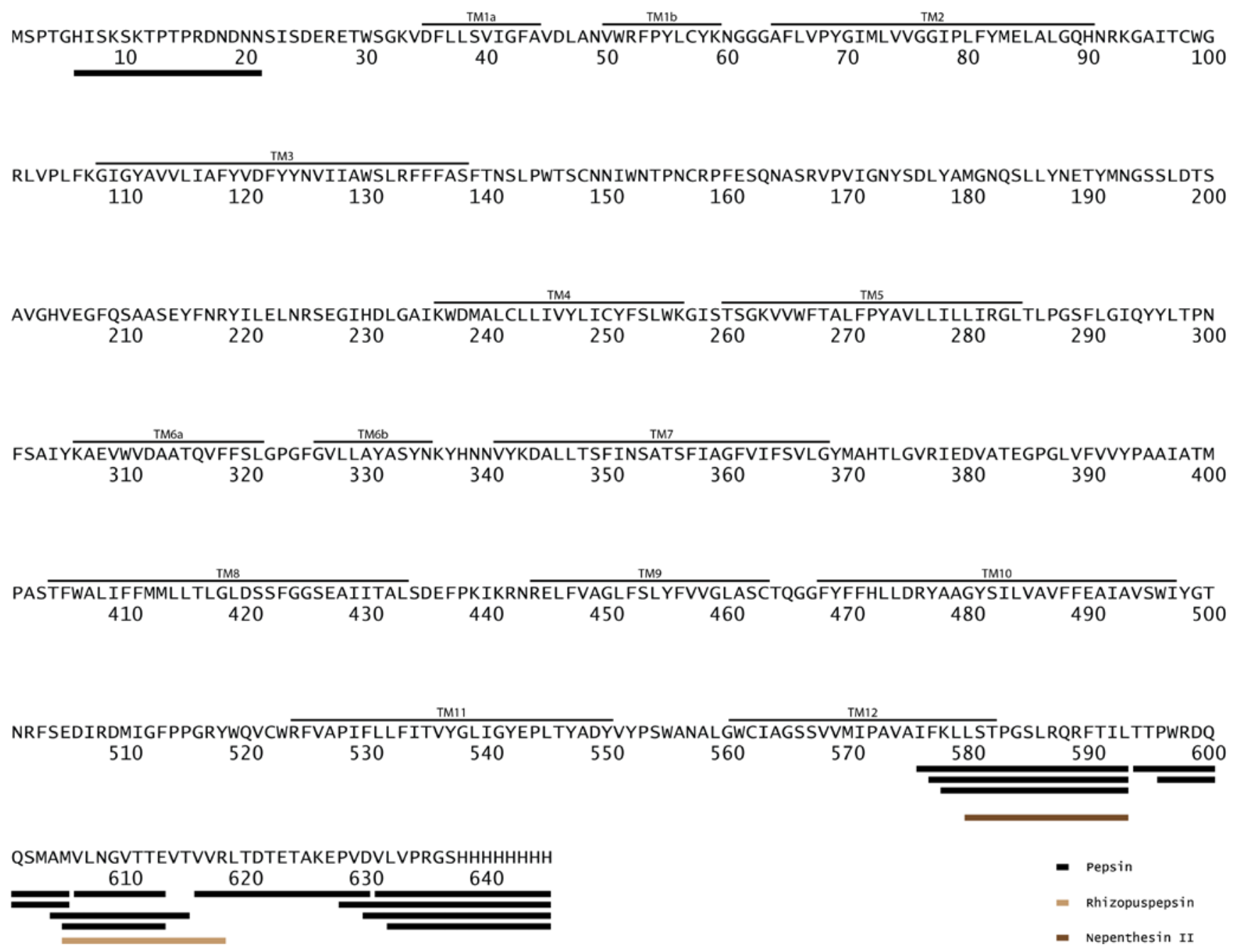

Figure S-8. Sequence coverage of DAT following in-solution digestion. The digestion of DAT resulted in 14 identified peptides covering $13.3 \%$ of the sequence following in-solution digestion by pepsin (black). In-solution digestion using rhizopuspepsin (light brown) and nepenthesin II (dark brown) were largely unsuccessful resulting in less than $5 \%$ of the sequence coverage. Digestion by nepenthesin I on DAT was not performed in solution. 

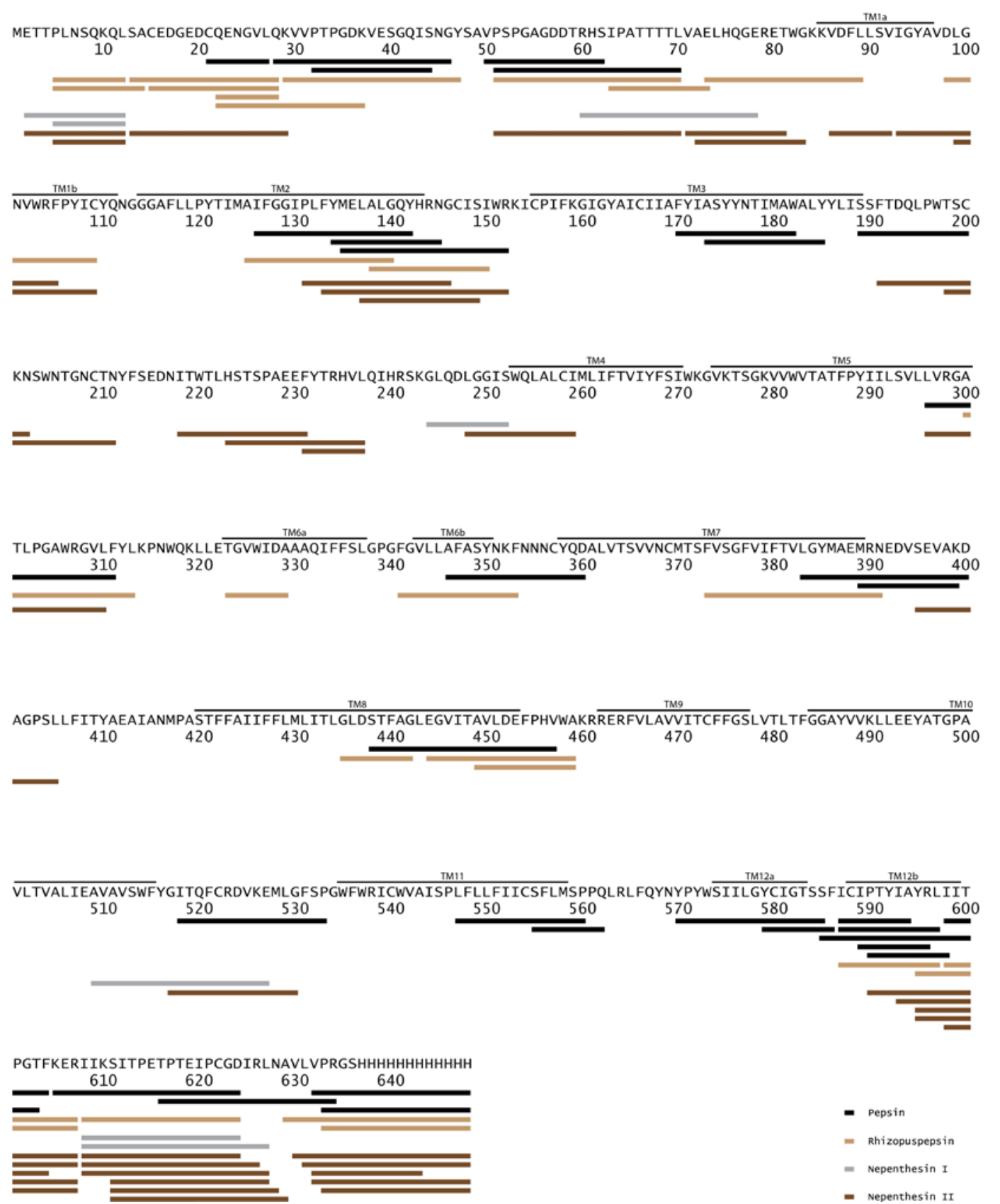

Figure S-9. Sequence coverage of SERT following in-solution digestion. The digestion of SERT resulted in 31 identified peptides covering 43.5\% of the sequence following in-solution digestion by pepsin (black); 26 identified peptides covering 39.4\% of the sequence following in-solution digestion by rhizopuspepsin (light brown); 7 identified peptides covering $12 \%$ of the sequence following in-solution digestion by nepenthesin I (gray); 37 identified peptides covering $40 \%$ of the sequence following in-solution digestion by nepenthesin II (dark brown). 
Table S-1. Extended overview of the digestion results obtained by the different proteases

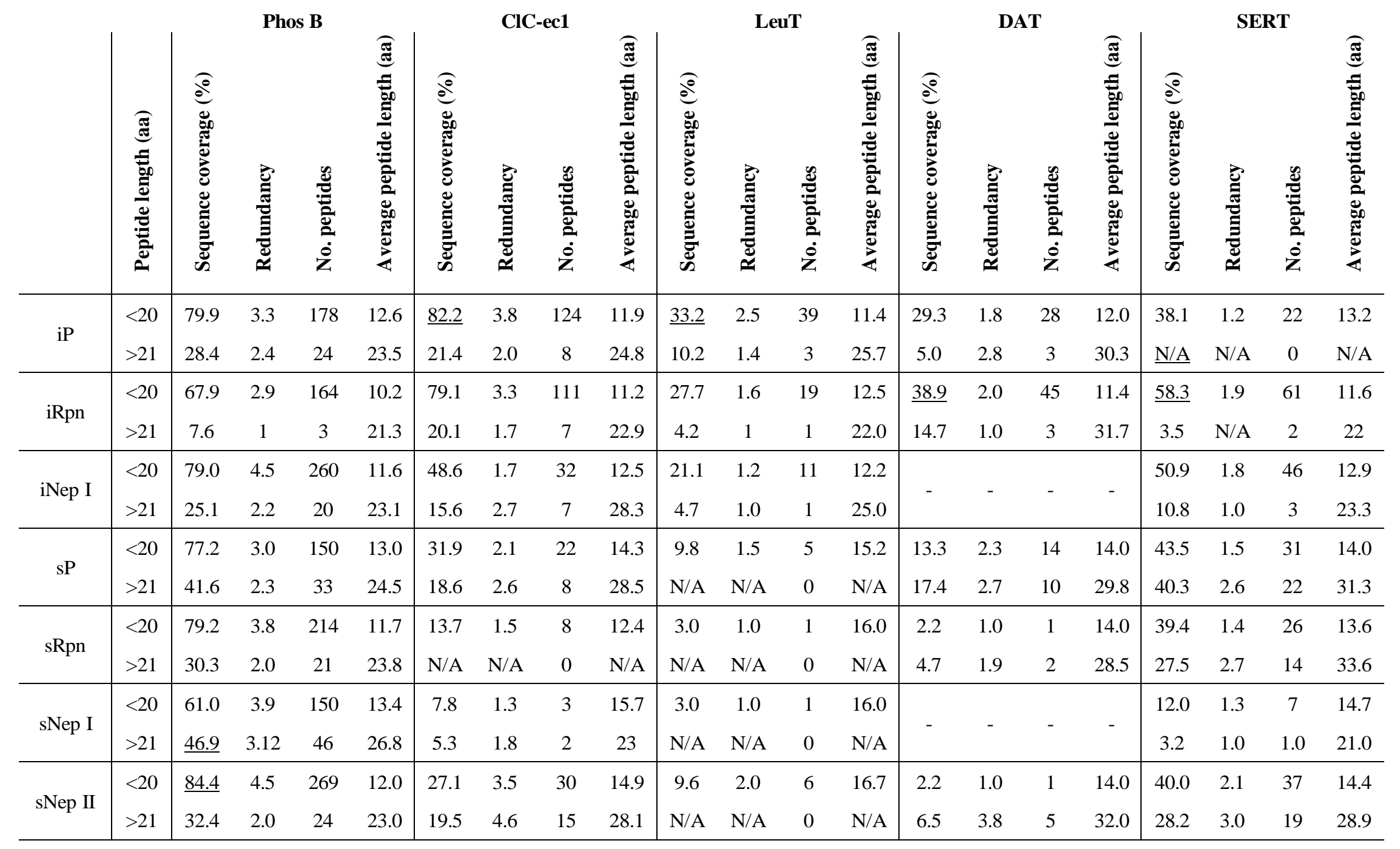

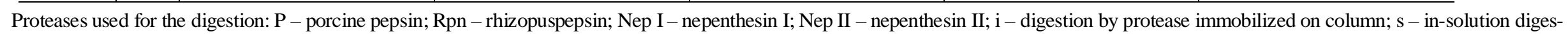

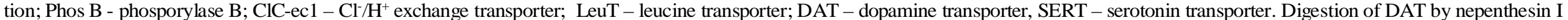

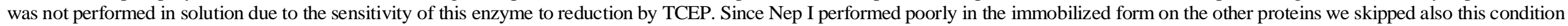

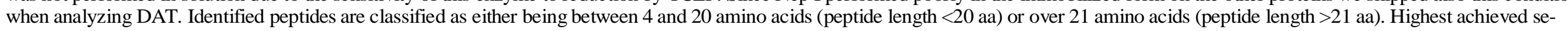

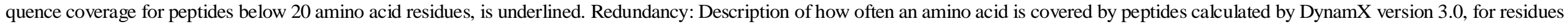

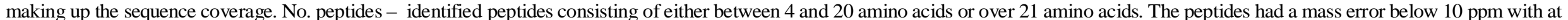

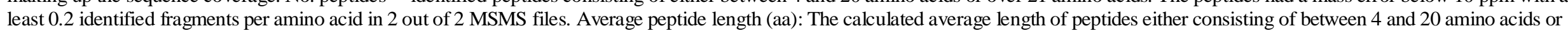
over 21 amino acids, for each respective protein. 
Table S-2. Comparison of the effect of different quench conditions on the digestion of phosphorylase B

\begin{tabular}{|c|c|c|c|c|c|c|c|c|c|c|c|c|c|c|c|c|c|c|c|c|}
\hline & \multicolumn{4}{|c|}{ PBS, Q1 } & \multicolumn{4}{|c|}{ PBS (Lip+CHS), Q1 } & \multicolumn{4}{|c|}{ PBS, Q2 } & \multicolumn{4}{|c|}{ PBS, Q3 } & \multicolumn{4}{|c|}{ PBS, Q4 } \\
\hline & 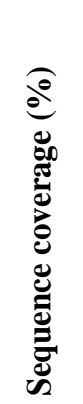 & 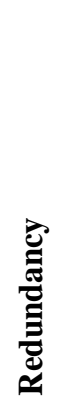 & 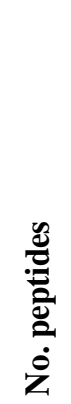 & 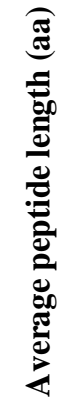 & 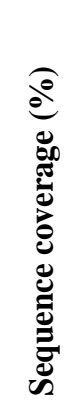 & 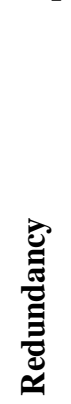 & 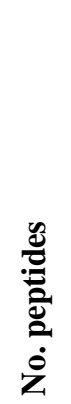 & 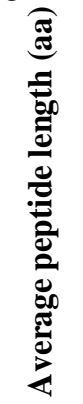 & 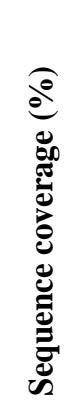 & 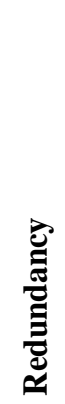 & 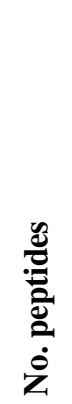 & 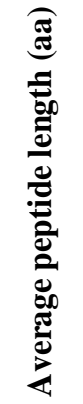 & 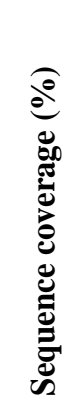 & 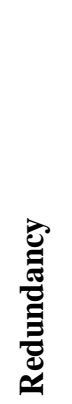 & 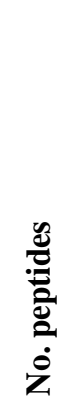 & 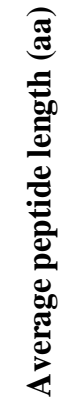 & 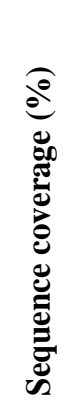 & 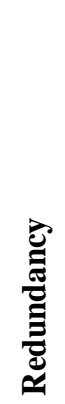 & 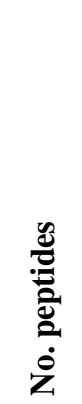 & 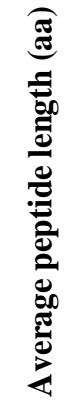 \\
\hline iP & 75.8 & 3.5 & 174 & 12.8 & 75.9 & 3.8 & 193 & 12.7 & 72.3 & 3.6 & 159 & 13.9 & 73.8 & 4.1 & 190 & 13.4 & 70.9 & 4.1 & 170 & 14.3 \\
\hline iRpn & 19.1 & 1.8 & 36 & 8.3 & 20.9 & 1.7 & 36 & 8.5 & 43.1 & 2.9 & 94 & 11.3 & 28.3 & 2.7 & 66 & 9.6 & 42.5 & 2.6 & 72 & 12.8 \\
\hline iNep I & 70.0 & 4.2 & 218 & 11.3 & 73.0 & 4.6 & 254 & 11.2 & 74.8 & 3.6 & 161 & 13.9 & 73.6 & 4.5 & 234 & 11.9 & 61.5 & 3.0 & 117 & 13.2 \\
\hline sNep II & 69.8 & 4.4 & 182 & 14.3 & 72.2 & 4.5 & 189 & 14.4 & 65.1 & 3.0 & 99 & 16.8 & 70.4 & 4.7 & 179 & 15.4 & 44.1 & 3.3 & 68 & 17.7 \\
\hline
\end{tabular}

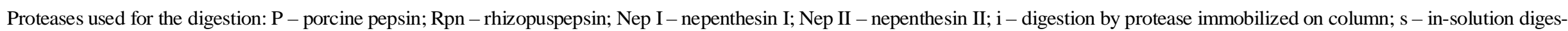

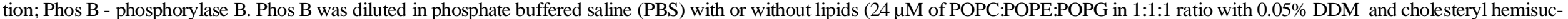

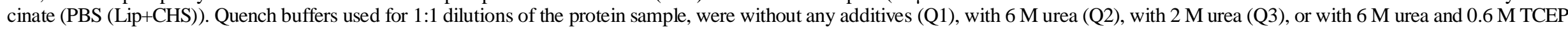

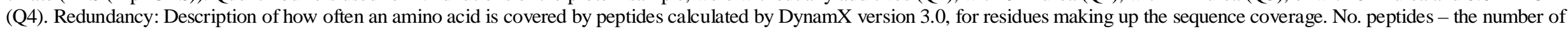

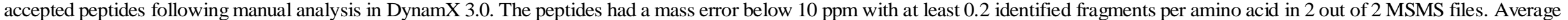
peptide length (aa): The calculated average length of all accepted peptides. 